\title{
PROJETO HABITAT - OFICINAS DE CAPACITAÇÃO PARA CONSTRUÇÃO CIVIL EM VIÇOSA-MG
}

\author{
Cleverson Alves de Lima1, \\ Carolina Santos Ribeiro', \\ Annie Akemi Palandi Yanaga ${ }^{3}$, \\ Ana Luísa de Araújo Tarôcot, \\ Geraldo Browne Ribeiro Filho ${ }^{5}$ \\ Aline Werneck Barbosa de Carvalho ${ }^{6}$
}

\section{RESUMO}

A cidade de Viçosa - MG possui uma considerável população de baixa renda, ocupando áreas de risco sócio-ambiental, cujas condições de moradia, renda, higiene e habitabilidade são bastante precárias. O presente projeto, Habitat - Oficina de capacitação para construção civil em Viçosa - MG, surgiu para complementar os trabalhos do projeto Habitat - Ação imediata, o qual abrange toda a área urbana do município e consiste em dar orientação as famílias que recebem doação de materiais de construção pelo "Programa de Melhoria Habitacional" desenvolvido pela Secretaria Municipal de Assistência Social da Prefeitura Municipal. O projeto ministra curso de capacitação em construção civil direcionados para pedreiros e serventes com pouca ou nenhuma

\footnotetext{
${ }^{1}$ Graduando de Engenharia Civil na Universidade Federal de Viçosa (UFV). E-mail: cleverson. lima@ufv.br

${ }^{2}$ Graduando de Arquitetura e Urbanismo na UFV. E-mail: carolribeiroarq@yahoo.com.br

${ }^{3}$ Graduando de Arquitetura e Urbanismo na UFV. E-mail: annieyanaga@hotmail.com

${ }^{4}$ Graduando de Arquitetura e Urbanismo na UFV. E-mail: analuisataroco@hotmail.com

${ }^{5}$ Professor Adjunto, Doutor, do Departamento de Arquitetura e Urbanismo da UFV. E-mail: gbrowne@ufv.br

${ }_{6}^{6}$ Professora Adjunto, Doutora, do Departamento de Arquitetura e Urbanismo da UFV. E-mail: abarbosa@ufv.br
}

\begin{tabular}{l|l|l|l|l}
\hline Revista Extensão \& Cidadania & Vitória da Conquista & v. 1, n. 2 & p. 155-171 & jul/dez. 2013 \\
\hline
\end{tabular}


experiência com obras. Logo, $\mathrm{O}$ foco do presente trabalho é promover a inclusão social, geração de renda e ensinar as boas práticas construtivas, logo que foi observado, nos trabalhos de vistoria do próprio projeto, obras executadas sem planejamento, sem orientação técnica e sem o devido cuidado com os materiais, gerando desperdício e aumentando os custos das obras.

Palavras-chave: Capacitação técnica. Construção civil. Habitação popular.

\begin{abstract}
Viçosa - MG has a sizable low-income population, occupying the areas of social and environmental risk, whose housing conditions, income, health and housing are quite precarious. This project, Habitat - Training for Construction in Viçosa - MG, emerged to complement the work of the Habitat - Immediate Action which covers the whole urban area and consists of instruct families that families receive donated materials construction by "housing Improvement Program" developed by the Municipal Social Assistance, with actions related to the preparation of architectural project and monitoring construction, renovations, additions and constructive solutions to problems in housing. The Habitat - Training for Construction minister training course targeted to builders and servants with little or no experience in construction work. Therefore, the focus is to promote social inclusion, income generation and teach the good construction practices, observed in inspection of the Habitat project itself, works performed without planning, without technical guidance and proper care of materials generating these waste and increasing the cost of works.
\end{abstract}

Keywords: Technical training. Construction. Popular housing.

\title{
Introdução
}

O projeto de extensão universitária intitulado $H A B I T A T$ - Ação Imediata, iniciado em julho de 2008 pelo Departamento de Arquitetura e Urbanismo da Universidade Federal de Viçosa - MG (UFV), que opera em conjunto com o Departamento de Habitação da Prefeitura Municipal de Viçosa, prestando assessoria técnica nas áreas de arquitetura e urbanismo e engenharia civil, às famílias contempladas com doação de materiais de construção pelo Programa de Melhoria Habitacional. Esse Programa visa atender população de baixa renda, que ocupa áreas de risco sócio-ambiental, cujas condições de moradia, renda, higiene e habitação são inadequadas. 
Esse projeto surgiu em razão da demanda do Departamento de Habitação e Urbanismo ao constatar que as familias participantes do Programa de Melhoria Habitacional não estavam utilizando os materiais de construção corretamente. Como forma de coibir ou minimizar a situação, foram desenvolvidas as seguintes ações: elaboração de diagnóstico dos serviços a serem executados, projeto arquitetônico de reforma ou construção, orientação na construção ou reforma e elaboração de orçamento.

Por intermédio do programa citado, a prefeitura doa os materiais, mas não se responsabiliza por seu uso. Dessa forma, as famílias contempladas são inteiramente responsáveis pela construção ou reforma de suas moradias. Entretanto, as condições socioeconômicas dessas famílias não permitem a contratação de um profissional habilitado para fazer o acompanhamento da obra. Logo, ela é realizada no sistema de autoconstrução ou com mão-de-obra com baixa qualificação, o que, somado ao pouco ou nenhum conhecimento sobre as boas práticas construtivas, contribuem ainda mais para o desperdício do material recebido.

Visando minorar a situação e melhorar as técnicas construtivas, o Projeto HABITAT - Ação Imediata sugeriu um incremento na parceria com a Secretaria de Assistência Social, propondo o desenvolvimento de oficinas para atender aos pedreiros e serventes que atuam em suas comunidades, compartilhando os conhecimentos adquiridos sobre as práticas construtivas. Destarte, buscou-se reduzir o desperdício dos materiais de construção. Em seguida, veiculado a esse, surgiu o Projeto HABITAT - Oficinas de Capacitação para Construção Civil, o qual visa suprir a demanda do citado programa de melhoria habitacional objetivando o uso adequado dos materiais doados, criando a possibilidade dos participantes aumentarem suas rendas. Esse projeto foi destacado em duas vertentes sendo uma com as atividades de vistoria e orientação técnica para as famílias cadastradas no programa de melhoria habitacional, e a outra dentro de um programa de qualificação do trabalhador para a construção civil. 
Para a montagem das oficinas recorreu-se à experiência do Curso Intensivo de Preparação de Mão-de-obra Industrial (CIPMOI), oferecido há mais de 50 anos pela Escola de Engenharia da Universidade Federal de Minas Gerais (UFMG). Os alunos que estavam vinculados ao projeto Habitat - Ação Imediata deslocaram-se até Belo Horizonte - MG, para visita à sede e, por conseguinte, lhes foram apresentados os programas dos cursos, as metodologias utilizadas, bem como disponibilizados os materiais didáticos. Além disso, participaram ativamente do processo seletivo de candidatos para conhecerem in loco a metodologia utilizada. De posse do conhecimento adquirido, foram realizadas várias reuniões para discussão, planejamento do projeto e adaptações dos materiais à realidade de Viçosa - MG.

Figura 1 - Entrevista com candidato a capacitação CIPMOI - UFMG

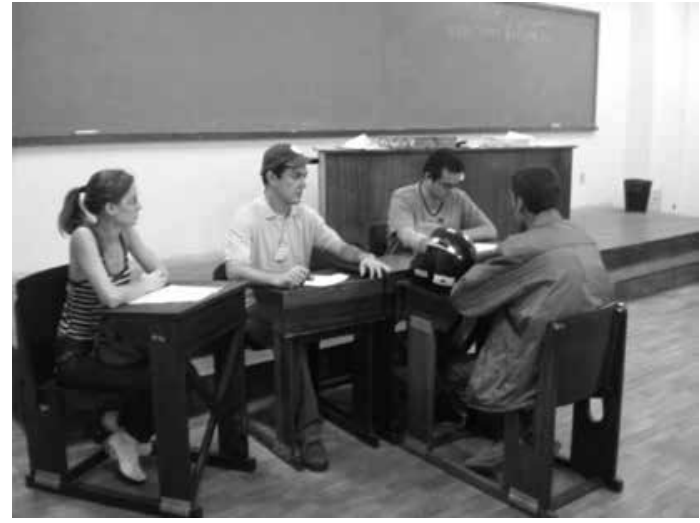

Fonte: Arquivo do Projeto.

Por conseguinte, foi feita a divulgação do projeto através dos postos de saúde da família (PSFs), programas assistenciais da prefeitura (Bolsa família, Pro jovem etc.), jornais, rádio local e nas comunidades. Marcou-se uma reunião para apresentação dos objetivos do curso aos interessados; uma prova básica de conhecimentos gerais para conhecer o nível dos candidatos, seguido de entrevista com a psicóloga da secretaria de assistência social e entrevista técnica com um instrutor para avaliar o conhecimento técnico do aspirante. As aulas seriam realizadas em 
duplas, com estudantes de arquitetura e urbanismo e engenharia civil, que ministram aulas das referidas disciplinas, orientados por professores do Departamento de Arquitetura e Urbanismo da Universidade Federal de Viçosa.

Iniciou-se, em agosto/2009, a primeira turma de capacitação de mão-de-obra para construção civil, a qual constou de 12 alunos, visando conhecer as necessidades dos pedreiros e serventes inscritos na capacitação. Logo depois, abordaram-se cinco temas que foram distribuídos em 15 horas semanais: tecnologia da construção civil, matemática básica, leitura de projeto arquitetônico, leitura de projeto estrutural e noções de hidráulica/eletricidade cuja carga horária total do curso correspondeu a 200 horas.

$\mathrm{Na}$ segunda turma, os cursos foram aperfeiçoados com base nas necessidades dos alunos da primeira turma. Foram inseridos módulos com noções de informática e discussões livres sobre cidadania. Esses módulos foram bem aceitos pelos participantes, uma vez que os colocavam em contato com tecnologias antes restritas aos técnicos de engenharia e arquitetura. Assim, puderam visualizar e entender a concepção e estruturação de um projeto. No módulo de Cidadania discutiu-se sobre os direitos individuais de cada trabalhador da construção civil como também a higiene, a saúde, além de direitos e deveres básicos de cada cidadão.

A procura por vagas nos cursos começou a crescer, principalmente devido à indicação dos ex-alunos que constataram a seriedade do projeto e os benefícios que o estudo continuado pode trazer. Embora a aceitação da capacitação para a construção civil nas comunidades apresentou-se crescente, para muitos existia uma dificuldade em conciliar o curso com o trabalho, logo que sua realização acontecia ao longo de um semestre com aulas diárias das 19 às 22 horas. Por conta disso, notou-se que havia uma evasão de alguns alunos que, geralmente, mantinham uma carga horária de trabalho das 7 às 17 horas. Para mitigar e estimulálos, os organizadores buscaram apoio da Prefeitura Municipal afim de propiciar algum incentivo e assim, manter os regulares no curso; para esses, seria fornecida uma cesta básica mensal. 
Ressaltamos que ao longo do curso são realizadas avaliações em todas as disciplinas para observar o desenvolvimento e diagnosticar as maiores dificuldades dos alunos. As avaliações acontecem em reuniões nas quais eles são instigados a expor suas críticas e sugestões a fim de melhorar os seus conhecimentos. No final, são emitidos certificados para aqueles que foram assíduos e apresentaram bom desempenho. Nessa ocasião, realiza-se uma confraternização na qual são convidados todos os instrutores voluntários, coordenadores, alunos e familiares.

Figura 2 - Confraternização no final do curso
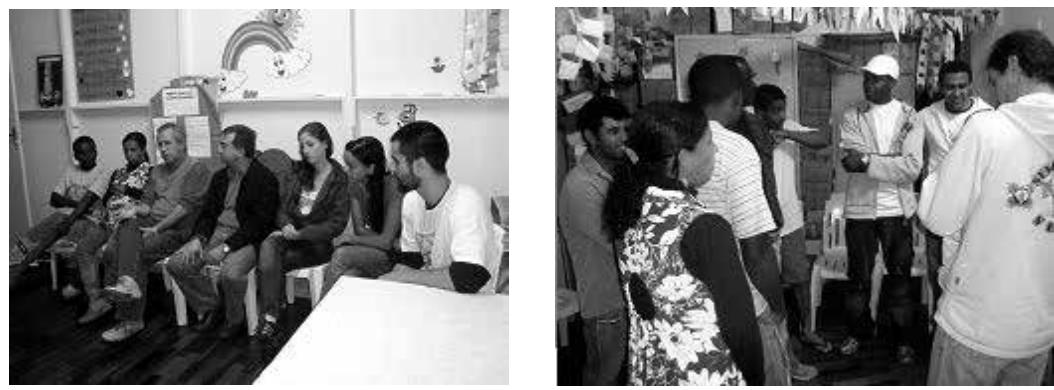

Fonte: Arquivo do Projeto.

Observa-se que as ações têm contribuído para proporcionar melhor qualidade de vida aos participantes das oficinas. Isso deve-se ao oferecimento de conhecimento técnico que considera a situação vivenciada por cada um, o aumento da renda familiar através de promoção na empresa ou inserção de alguns no mercado de trabalho como também a motivação para voltar a estudar, além do intercâmbio de conhecimentos entre professores e alunos.

\section{Organização do projeto}

O projeto foi desenvolvido na Universidade Federal de Viçosa (UFV) sob coordenação de dois professores do Departamento de Arquitetura e Urbanismo com colaboração de dois professores, sendo um do Departamento da Engenharia Civil e outro da (informar o 
departamento), e dele participam 29 alunos dos cursos citados como também de Engenharia de Agrimensura. Esses estudantes são colocados em contato direto com uma realidade socioeconômica e ambiental que, muitas vezes, lhes são desconhecidos, mas que está presente, de forma mais ou menos aparente, nas cidades brasileiras. Essa vivência, certamente, tem contribuído para sua própria formação como verdadeiros cidadãos. De forma semelhante, acontece com as pessoas atendidas tanto pelo projeto $H A B I T A T$ - Ação Imediata quanto pelas pessoas atendidas pelo projeto HABITAT - Oficinas de Capacitação para a Construção Civil.

Muitas vezes esquecidas pelos programas governamentais, ou atendidas de forma assistencialista, elas têm, nesse projeto, oportunidade de receber muito mais do que materiais de construção. Orientações e conhecimentos, muitas vezes considerados simples, como indicação sobre a melhor localização para dispor uma janela, ou uma porta, em função das condicionantes climáticas, ou sobre aspectos funcionais e construtivos da edificação, como banheiro, cozinha, telhado, muro de arrimo, etc. contribuem significativamente para melhorar as condições da habitação e, como conseqüência, a qualidade de vida.

A seleção dos atendidos pelo projeto Habitat - Oficinas de Capacitação é feita mediante análise criteriosa da assistente social e psicóloga da prefeitura, além da participação dos instrutores que ministram as aulas, os quais consideram as condições socioeconômicas, alfabetização e conhecimento técnico de cada um que se interessa pela capacitação. Mesmo com curto tempo de funcionamento, o projeto já alcançou resultados expressivos e mostrou seu potencial ao impactar positivamente as famílias de renda mais baixa de Viçosa em suas necessidades mais básicas, que são as condições dignas de habitação.

\section{O projeto - concepção}

O projeto Habitat - Ação Imediata começou a ser delineado em março de 2008, quando um representante da Secretaria de Assistência Social entrou em contato com professores do Departamento de 
Arquitetura e Urbanismo da UFV objetivando envolver os alunos do curso no Programa de Melhoria Habitacional, que consistia na doação de material de construção a famílias de baixa renda e em situação de risco socioambiental.

Inicialmente, a preocupação da Secretaria era com o uso inadequado do material, tanto no armazenamento quanto em sua aplicação nas obras. Havia aproximadamente dois anos que a prefeitura fornecia materiais de construção gratuitamente para que as próprias famílias reformassem suas casas. Até então, cerca de 430 famílias já haviam sido atendidas pelo Programa. Tendo em vista as condições socioeconômicas dessas famílias, a construção se dava pelo sistema de autoconstrução ou com a contratação de mão-de-obra com baixa qualificação.

Em reunião realizada entre os professores coordenadores do projeto e a secretaria de Assistência Social, discutiu-se sobre o formato do projeto, seus objetivos, como os alunos poderiam atuar e também sobre a importância de envolver os estudantes do curso de Engenharia Civil, Engenharia de Agrimensura e Arquitetura e Urbanismo para trabalharem em conjunto. Nesse sentido, foi fundamental o envolvimento de dois estudantes do curso de Engenharia Civil que estavam estagiando na secretaria há cerca de um ano, e um estudante do curso de Arquitetura e Urbanismo, como coordenadores das equipes de trabalho. A experiência e a capacidade de liderança desses alunos foram decisivas para a formação da equipe - atualmente composta por 29 estudantes voluntários - e para o traçado das primeiras linhas de ação. Tomaram-se como referência as experiências relatadas pelo projeto de extensão Projeto Habitat - Consultório de Arquitetura no Bairro Nova Viçosa desenvolvido no Departamento de Arquitetura e Urbanismo da UFV.

A renda familiar da maioria dos atendidos é de 1/4 (um quarto) do salário mínimo ou inferior a esse montante. Grande parte dos atendidos possui como única fonte de renda o benefício do Programa Bolsa-Família. Para avaliar de forma mais precisa as condições sociais, econômicas e ambientais nas quais esse projeto se insere, tornase relevante informar que, ainda que Viçosa tenha uma das mais 
conceituadas universidades do país, não difere de outros municípios brasileiros no que diz respeito às desigualdades socioespaciais.

\section{A cidade de Viçosa-MG}

De acordo com Cruz et al. (2008), o Instituto Brasileiro de Geografia e Estatística (IBGE), em 2007, estimou a população do município em 70.404 habitantes, dos quais 92,38\% residem no perímetro urbano e 7,62\% na área rural. Localizado na Zona da Mata de Minas Gerais, o município possui área de $299 \mathrm{~km}^{2}$ e está situado em um planalto cujo relevo apresenta-se acidentado, composto por cadeias de montanhas agrupadas, com altas declividades, formando vales estreitos.

A área urbana está localizada em um vale, com altitude próxima a $649 \mathrm{~m}$, e cerca de $40 \%$ do espaço construído está situado em área com declividade de até $15 \% ; 20 \%$ desse espaço está situado em área com declividade entre 15 e $30 \%$ e os $40 \%$ restantes estão situados em terrenos com declividades iguais ou superiores a 30\% (MANN; SIDDLES; PALERMO, 1993, p. 21). O município é cortado pelos rios Turvo Sujo e Turvo Limpo, que se confluem na região de Duas Barras, nos limites de Viçosa com os municípios de Porto Firme e Guaraciaba (RIBEIRO FILHO, 1997).

A partir do final da década de 1960, Viçosa sofreu intenso processo de urbanização em razão da federalização e da significativa expansão da UFV, tendo essa recebido aumento substancial de recursos financeiros para sua expansão, que resultou na criação de novos cursos, contratação de novos professores e de técnicos administrativos. Os números apresentados abaixo fornecem uma dimensão das implicações desse crescimento para o espaço urbano da cidade.

Em 1960, a população urbana, segundo dados do IBGE, era de 9.342 habitantes. Em 1970 aumentou para 17.000 habitantes, representando uma taxa de mais de $80 \%$ em dez anos. Em 1980, a mesma se elevou a 31.179 habitantes, representando novamente uma elevada taxa de crescimento de mais de $80 \%$, no mesmo período. $\mathrm{Na}$ década de 1990, a taxa de crescimento da população urbana diminuiu e, mesmo assim, apresentou-se elevada, quase atingindo 50\%. Nas 
décadas seguintes essas taxas se acomodam na faixa de 30\% (RIBEIRO FILHO, 1997; CRUZ et al., 2008, p. 20).

$O$ processo de rápida urbanização, sem o devido aporte governamental na provisão de infraestruturas e planejamento, contribuiu significativamente para o aumento das desigualdades socioespaciais já existentes, bem como para a degradação do espaço urbano natural e construído. A cidade se expandiu rapidamente em direção aos fundos de vale e áreas de encostas, sendo que tais ocupações se deram principalmente por famílias de baixa renda (RIBEIRO FILHO, 1997).

Dentre os bairros contemplados pelo programa Bolsa Família, na maioria das vezes, são os mais populosos. Nova Viçosa é um deles, bem como a zona rural, onde se localiza a comunidade do Buieié. Segundo informações prestadas por técnicos da Secretaria Municipal de Assistência Social, uma média de 65\% das residências dessas comunidades mais carentes são chefiadas por mulheres e a média de filho é de 3 a 4 ainda menores.

Figura 3 - Residências em Buieié (zona rural) e no Bairro Nova Viçosa
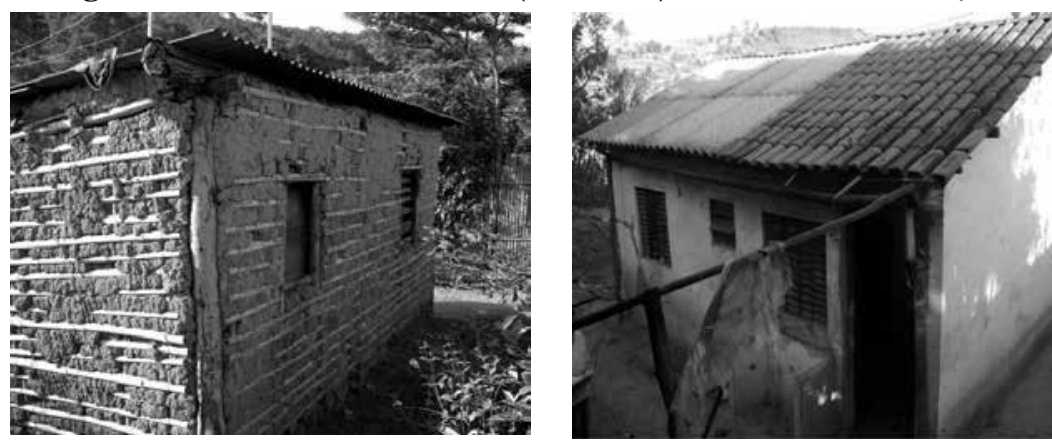

Fonte: Arquivo do Projeto.

Conforme Cruz et al. (2008), a renda per capita na região de Nova Viçosa (R \$ 169,38/mês) é seis vezes menor do que a da região Centro ( $\mathrm{R} \$ 995,36 /$ mês). Essa distorção entre centro e periferia evidencia-se também quando se analisam os dados relativos ao grau de instrução. O IBGE, em 2007, identificou, no Centro, que 20,62\% da população concluiu o segundo grau e 38,14\% superior completo, enquanto em Nova Viçosa, apenas 1,97\% apresenta segundo grau completo e 0,21\% superior completo (CRUZ et al., 2008). 
No que se refere às condições habitacionais, segundo ainda informações do IBGE relativas a 2007, 0,84\% dos domicílios do Centro possuíam quatro moradores por dormitório enquanto nos bairros Bom Jesus e Nova Era - bairros periféricos - essas taxa chega a 3,54\% e 3,77\%, respectivamente. Mesmo sendo um quadro simplificado das condições socioeconômicas de Viçosa, é possível imaginar as condições de vida das famílias acompanhadas (CRUZ et al., 2008).

Além de atender a demanda da Secretaria Municipal de Assistência Social, os participantes do projeto estão assumindo novas responsabilidades ao procurar antecipar-se à doação do material, realizando, previamente, levantamentos das reais necessidades das famílias, baseados em projetos arquitetônicos também elaborados previamente.

Assim, periodicamente, a Secretaria Municipal organiza reuniões com a participação das equipes do projeto e com as famílias, visando apresentar o projeto Habitat e mostrar a importância de se elaborar o projeto arquitetônico antes da realização das obras. Houve boa aceitação da ideia e assim, as famílias interessadas foram cadastradas.

Figura 4 - Equipe de Vistorias - Realizando acompanhamento de construção.
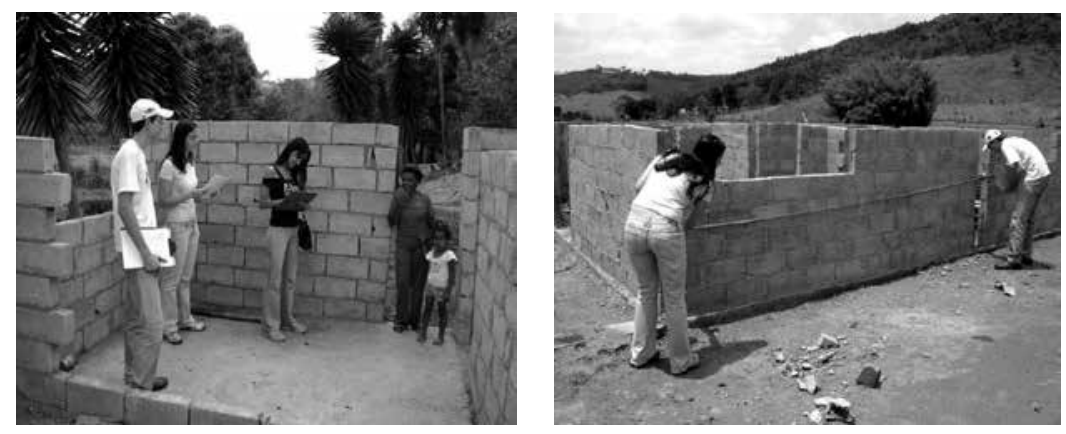

Fonte: Arquivo do Projeto.

Ao longo da implantação desse projeto de extensão verificouse a necessidade de criar outra vertente denominada de "projetos especiais", tendo em vista a demanda da prefeitura no que diz respeito a elaboração de projetos arquitetônicos e prestação de assessoria técnica para famílias que não estavam incluídas no Programa de Melhoria Habitacional, além de outras famílias cadastradas no banco 
de dados da Defesa Civil municipal, as quais seriam deslocadas de suas residências por viverem em área de risco, cujas habitações foram condenadas, e que receberam lotes doados pela prefeitura. Esses novos grupos foram vistoriados e receberam projetos arquitetônicos para construírem suas novas residências seguindo a mesma metodologia de trabalho do projeto HABITAT - Ação Imediata. Além dos estudantes de arquitetura e urbanismo, os trabalhos contam com a assistência de dois estudantes do curso de engenharia de agrimensura, responsáveis pelos levantamentos topográficos. Numa segunda fase, os estudantes de engenharia civil realizam os projetos complementares (estrutural, hidráulico, elétrico), bem como orçamento. Os alunos envolvidos nessas atividades trabalham em uma equipe de projetos em que se dedicam de forma exclusiva, contudo, é permitido o revezamento dos grupos para que todos possam vivenciar as experiências.

Outros passos importantes serão dados no futuro. Articulase uma parceria com o Instituto de Planejamento Urbano Municipal (IPLAM) para implantação do programa de engenharia e arquitetura públicas ${ }^{7}$, que visa assistir as famílias com renda inferior a três salários mínimos, fornecendo assessoria técnica gratuita em engenharia e arquitetura.

\section{Metodologia}

Todas as atividades propostas pelo projeto HABITAT Oficinas de Capacitação para Construção Civil, contam com a parceria da Secretaria de Assistência Social, que fornece material didático para os alunos, disponibiliza a sala de aula com equipamentos necessários e disponibiliza psicóloga e assistente social para acompanhar todo o processo de implementação e funcionamento das oficinas. metodologia a utilizada tem como referência a experiência de 50 anos de atividade do CIPMOI - UFMG.

\footnotetext{
${ }^{7}$ Programa criado pelo Conselho de Engenharia e Arquitetura (CREA) junto com o Governo Federal, que visa prestar assistência técnica na elaboração e execução de projetos.
} 
Como dito anteriormente, nas aulas serão abordados sete temas, distribuídos em 15 horas semanais: tecnologia da construção civil, informática básica, matemática básica, leitura de projeto arquitetônico, leitura de projeto estrutural, noções de hidráulica/eletricidade e discussões livres (contem noções de cidadania e palestras proferidas por convidados), totalizando 200 horas ao final do curso.

Figura 5 - Aula durante as Oficinas de Capacitação para Construção Civil

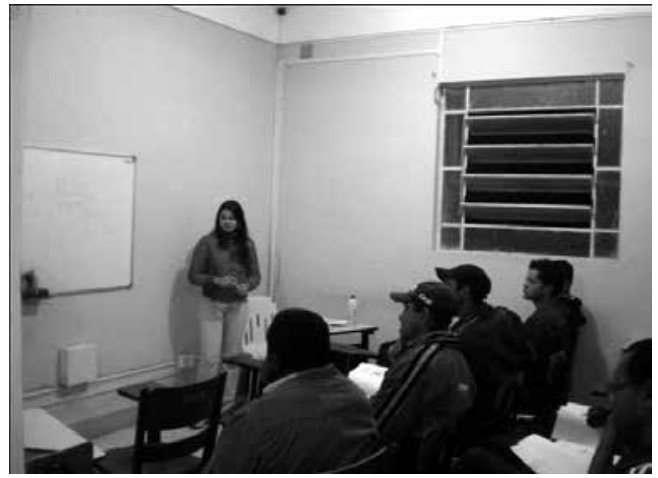

Figura 6 - Aula de Matemática

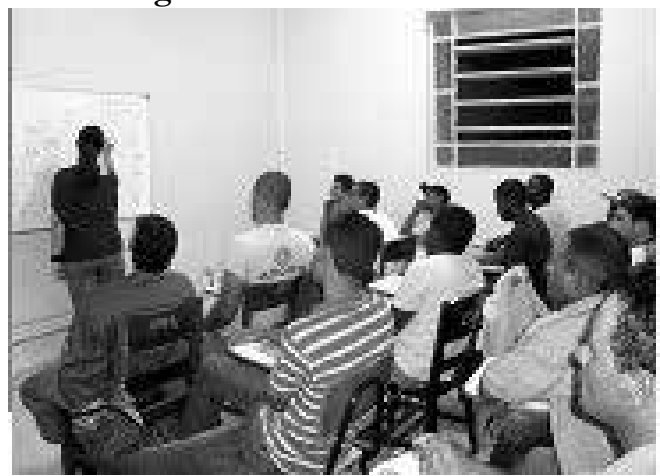

Fontes: Arquivo do Projeto.

Durante o período, os estudantes, realizaram a preparação de material didático/pedagógico com assessoria do corpo de profissionais do CIPMOI, e passará por processo de adequação a realidade local, sob supervisão dos professores participantes do projeto. As apostilas 
contendo o conteúdo programático sobre cada tema esta sendo confeccionada e serão disponibilizadas gratuitamente aos participantes.

\section{Resultados alcançados}

Em 2009 foram oferecidas uma turma-piloto com 12 alunos matriculados e duas turmas no ano de 2010, contendo 25 alunos cada turma. Foram capacitados, até então, 6 alunos na primeira turma e 42 alunos nos dois semestres seguintes. A meta para 2011 era capacitar mais 50 alunos no ano. Todavia ocorreu que o programa de melhoria habitacional foi substituído pelo programa federal de habitação "Minha Casa, Minha Vida". Assim, as atividades das oficinas estão sendo reconfiguradas, para atender ao mesmo publico utilizando o cadastro do bolsa família.

Ademais, o trabalho foi agraciado pela Universidade Federal de Viçosa em 2008 e 2010, com o prêmio Arthur Bernardes - Mérito em Extensão; e também pela Fundação Banco do Brasil em 2009, que o certificou como uma tecnologia social efetiva, dentre mais de duas mil inscrições em concurso nacional.

Figura 7 - Correção de Provas em Sala de Aula

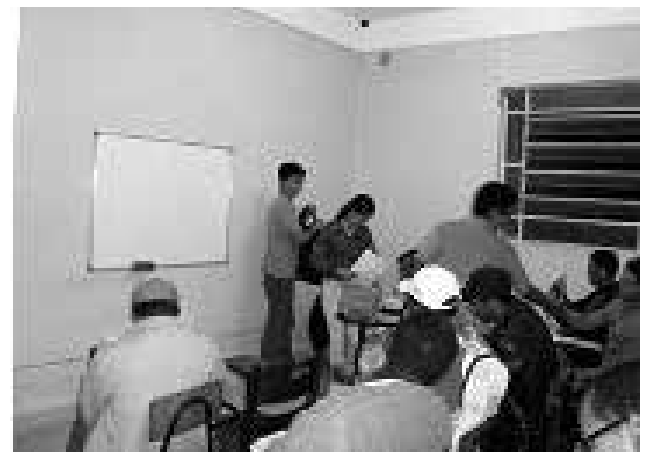


Figura 8 - Reunião com voluntários

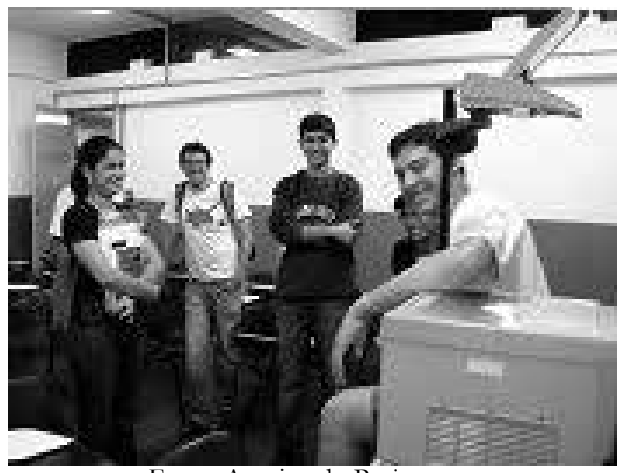

Fonte: Arquivo do Projeto.

\section{Impactos causados na comunidade}

Satisfação: foi observado, através das críticas recebidas durante as reuniões para avaliação do curso, que os alunos aprovaram a iniciativa e estão satisfeitos com a oportunidade oferecida de se estudar um tema específico e carente de opções. A satisfação se traduziu em recomendações a outros trabalhadores da construção, que devido a essa indicação, procuraram se informar a respeito do curso e da importância da atualização profissional. Uma parte dos novos alunos chegaram até o projeto Habitat por intermédio de recomendações.

Aumento da renda familiar: alguns alunos, após o curso, retornaram para comunicar que haviam sido promovidos ou que começaram a executar atividades que geralmente são realizadas por funcionários mais experientes no trabalho, aumentando assim a sua renda bruta final. Outros relataram que conseguiram uma colocação no mercado de construção civil, que está aquecido e necessitando de pessoas com conhecimento na área.

Motivação para voltar a estudar: o retorno a atividades de aprendizado motivou alguns alunos a voltar a estudar, pois a maior parte deles possui o ensino fundamental incompleto. Outros solicitaram mais materiais para continuar os estudos com intuito de tentar concursos públicos na prefeitura local. 
Intercâmbio de conhecimentos: considerando que os alunos possuem grande conhecimento adquirido através do trabalho prático, enquanto os instrutores possuem uma carga maior de conhecimento teórico, deu-se a troca de experiências.

Interação entre universidade e sociedade: o conhecimento técnico pôde ser transmitido para trabalhadores que, às vezes, nem possuem o ensino básico.

Credibilidade: a capacitação ganhou notoriedade e credibilidade junto aos construtores, devido, em partes, ao apoio do Departamento de Arquitetura e Urbanismo da Universidade Federal de Viçosa, da Prefeitura Municipal de Viçosa, e da dedicação dos voluntários que abordaram temas relevantes para os alunos do curso.

\section{Comunidade atingida}

Na figura abaixo, consta o mapa da cidade de Viçosa-MG, com destaque para as áreas oriundas dos alunos. Está destacado o Colégio de Viçosa, local em que ocorreram as aulas e a localização dos bairros de origem dos alunos que cursaram as oficinas desde a primeira turma.

Figura 9 - Mapa da cidade de Viçosa-MG

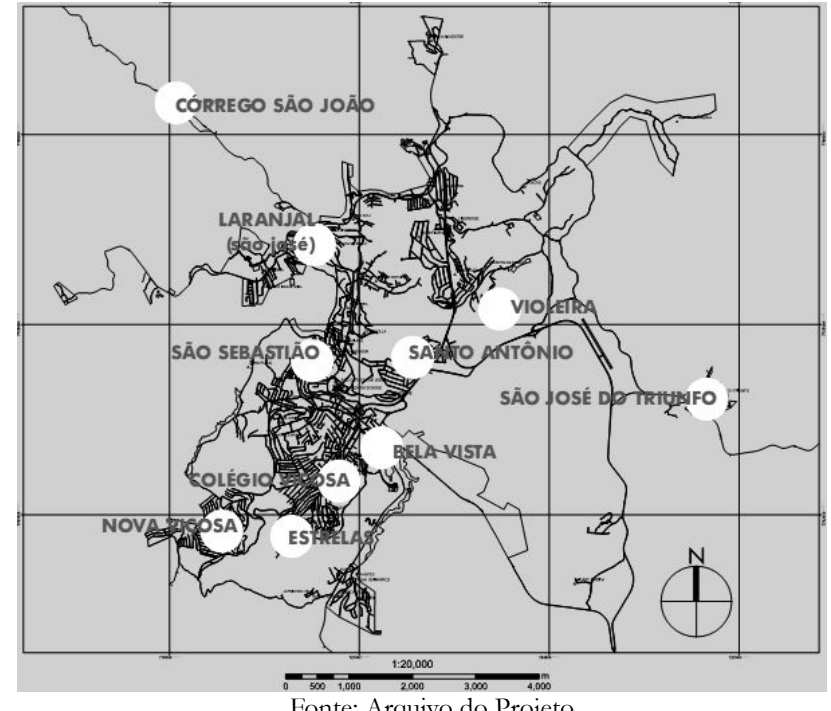

Fonte: Arquivo do Projeto. 
Observa-se que muitos dos alunos deslocavam-se de regiões periféricas e áreas rurais de difícil acesso até o Colégio de Viçosa para assistir as aulas diariamente. O projeto atendeu também a dois alunos que se deslocavam de uma cidade vizinha, Teixeiras - MG, que se inscreveram para fazer o curso.

\section{Referências}

CRUZ, Tancredo Almada; Alvarenga, Sonia Coelho; Carmo, Maria Inês do. Retrato social de Viçosa 2007. Viçosa, MG: CENSUS, 2008.

MANN, Jacqueline; SIDDLES, Martin; PALERMO, Frank. Planejando comunidades brasileiras: documentando a cidade. Halifax: Technical University of Nova Scotia, 1993.

RIBEIRO FILHO, Geraldo Browne. A formação do espaço construído: cidade e legislação urbanística em Viçosa, MG. 1997. Dissertação (Mestrado em Urbanismo) - PROURB/UFRJ, Rio de Janeiro, 1997. 